\title{
Recursos virtuais para o ensino presencial e remoto de Histologia
}

\author{
Tatiana Montanari \\ Departamento de Ciências Morfológicas, ICBS, UFRGS, t.montanari@bol.com.br
}

\begin{abstract}
Resumo: Os recursos virtuais Atlas digital de Biologia celular e tecidual (http://www.ufrgs.br/atlasbiocel) e auladehisto (http://www.ufrgs.br/auladehisto) foram desenvolvidos para apoiar o ensino presencial e remoto de Histologia nos cursos de graduação das Ciências Biológicas e da Saúde. A concepção pedagógica baseou-se na descrição da inteligência naturalista, em que o processamento de informações envolve o reconhecimento e a categorização de espécimes, habilidades importantes para a área morfológica. No design, as imagens foram privilegiadas, devido à relevância da informação visual nesse campo do conhecimento. A avaliação discente da primeira versão do atlas digital indicou que as imagens e os exercícios favoreceram a compreensão do conteúdo, em especial, a relação entre morfologia e atividade funcional da célula, objetivo cognitivo definido na estratégia pedagógica. As críticas dos alunos foram consideradas para a elaboração de uma nova versão do atlas com o conteúdo apresentado em PDF. Os exercícios criados com o programa Hot Potatoes foram publicados no ambiente virtual auladehisto. Ele exibe o conteúdo de Histologia em telas do PowerPoint para tornar a leitura mais dinâmica. A avaliação discente demonstrou que os recursos educacionais contribuíram para o processo de ensino-aprendizagem e apresentaram facilidade na navegação e qualidade das imagens. Espera-se, com o seu desenvolvimento, fomentar a qualificação do ensino das Ciências Morfológicas.
\end{abstract}

Palavras-chave: Biologia celular, Histologia, Morfologia, ensino, educação à distância.

\section{Virtual resources for Histology Classroom Teaching and E-learning}

\begin{abstract}
Atlas digital de Biologia celular e tecidual (http://www.ufrgs.br/atlasbiocel) and auladehisto (http://www.ufrgs.br/auladehisto) virtual resources were made to support Cell Biology and Histology teaching from Biological and Health Sciences courses. The pedagogical conception was based on the description of the naturalist intelligence, information processing on recognition and categorization of specimens, important capabilities for the morphological field. In design, the images were privileged, because the visual information is relevant in this field of knowledge. The evaluation of the first version of the digital atlas by students demonstrated the images and exercises facilitated the understanding of the subject, principally, the relationship between cell morphology and functional activity, cognitive aim defined in educational strategy. Their comments were considered for designing a new version of the atlas with the subject presented as PDF files. The exercises created by Hot Potatoes software were published at the virtual environment auladehisto. It exhibits the Histology subject in PowerPoint screens to become the lecture more dynamic. The evaluation by students demonstrated their contribution for the teaching-learning process, facility in the browsing and quality of the images. I hope contributing to improve Morphological Sciences teaching by these educational resources.
\end{abstract}

Keywords: Cell Biology, Histology, Morphology, teaching, e-learning. 


\section{INTRODUÇÃO}

A célula é a unidade estrutural e funcional básica dos seres vivos. As células organizamse em tecidos, e estes, em órgãos e sistemas. A Histologia estuda as células, os tecidos e os sistemas do organismo e correlaciona a sua estrutura com a sua função. A informação visual é de suma importância nessa disciplina. A maior parte do conhecimento adquirido nessa área (denominada Morfologia) foi obtida através da observação de células isoladas ou em cortes de tecidos ou órgãos. O microscópio de luz, o microscópio eletrônico de transmissão e o microscópio eletrônico de varredura são instrumentos importantes nessa investigação (Carvalho \& Recco-Pimentel, 2013; Ross \& Pawlina, 2016). No ensino dessa disciplina, não há como dissociar o conteúdo teórico das imagens obtidas nesses aparelhos. Tanto que, além das fotomicrografias (imagens obtidas ao microscópio de luz) e das eletromicrografias (obtidas ao microscópio eletrônico) que ilustram as aulas teóricas, geralmente metade da carga horária da disciplina é dedicada a atividades práticas, onde os alunos observam preparados permanentes ao microscópio de luz.

Tendo isso em vista os livros-texto apresentam geralmente fotografias e podem ser acompanhados por CD-ROM ou código de acesso a ambientes virtuais com imagens, vídeos e animações (Geneser, 2003; Stith, 2004; Alberts et al., 2010; Lowe \& Anderson, 2015). O custo elevado da publicação em colorido, no entanto, dificulta a sua aquisição pelo estudante ou pela biblioteca da instituição. Agravando esse cenário, há a sistemática redução da carga horária das disciplinas da área morfológica nas reformas curriculares dos cursos de graduação das Ciências Biológicas e da Saúde. As aulas práticas também são prejudicadas pela limitação de recursos para a montagem e a manutenção dos laboratórios de microscopia. As ferramentas de educação à distância surgem como alternativa para solucionar essas dificuldades, otimizando o tempo do aluno e do professor dedicado ao conteúdo e complementando o ensino presencial (Heidger et al., 2002; Santa-Rosa \& Struchiner, 2011).

Os recursos virtuais Atlas digital de Biologia celular e tecidual e auladehisto foram desenvolvidos com o objetivo de contribuir para o processo de aprendizagem no ensino presencial e remoto da disciplina de Histologia nos cursos de graduação das Ciências Biológicas e da Saúde. Espera-se, assim, contribuir para a qualificação do ensino das Ciências Morfológicas.

\section{METODOLOGIA}

A concepção pedagógica do Atlas digital de Biologia celular e tecidual baseou-se na teoria das inteligências múltiplas do neuropsicólogo norte-americano Howard Gardner, mais precisamente, na inteligência naturalista, descrita como o conjunto de habilidades mentais relacionadas a reconhecimento, classificação e categorização de espécimes (Gardner, 2005; Gardner, 2007). Pretendia-se contemplar as necessidades dos estudantes das disciplinas de Biologia celular e Histologia em reconhecer, comparar (e distinguir) e classificar as células (os tecidos ou os órgãos) conforme suas características morfológicas, como forma, constituição e coloração. Outro ponto importante é a inferência da atividade funcional da célula, que compõe determinado tecido e/ou órgão, pelo seu aspecto estrutural. Assim, no planejamento, priorizou-se a oferta de material visual de excelente qualidade, em que essas habilidades pudessem ser exercitadas e, no seu design, as imagens foram privilegiadas.

Foram selecionadas fotografias, obtidas em microscopia de luz e em microscopia 
eletrônica, das células e seus constituintes, dos tecidos e dos órgãos, provenientes do acervo de aulas práticas ou de projetos de pesquisa. Para acompanhá-las foram redigidas legendas com a descrição do material biológico, a técnica (ou coloração) utilizada e, sempre que possível, o aumento. A coleção foi organizada em três grandes tópicos: Célula, Tecidos e Sistemas, sendo subdivididos nos seus constituintes. Para o desenvolvimento do atlas digital inicialmente foi usado o programa Macromedia Flash, visando oferecer navegação hipertextual amigável e interativa. Uma seção de exercícios criados com o auxílio do software Hot Potatoes foi agregada.

Para verificar a sua aplicabilidade, foi utilizado como apoio didático-pedagógico no estudo extraclasse na disciplina de Biologia Celular do curso de Biologia Marinha. O atlas foi indicado no início do primeiro semestre letivo de 2008, sendo inclusive citado como uma das referências bibliográficas no plano de ensino. Os alunos foram informados que o avaliariam ao final do semestre. Seu endereço foi repetido conforme o andamento da matéria, solicitando o acesso do conteúdo abordado. Na data oportuna, os alunos receberam um questionário sobre os seguintes itens: relevância do objeto de aprendizagem para os objetivos e as necessidades cognitivas da disciplina, facilidade de orientação na navegação, recursos para valorizar as imagens (sinalização das organelas e estruturas com setas, clareza das legendas), contribuição dos exercícios para a aprendizagem e aplicação de conteúdos.

As críticas realizadas pelos alunos foram consideradas para a elaboração de uma nova versão do atlas digital, usando o Adobe Dreamweaver para construir a navegação e apresentando o conteúdo como arquivos $P D F$. O ambiente virtual auladehisto foi criado com o mesmo programa, exibindo o conteúdo de Histologia em telas do PowerPoint e os exercícios preparados com o Hot Potatoes. Ele foi utilizado no ensino presencial da disciplina Histologia do curso de Ciências Biológicas, no primeiro semestre letivo de 2016. Os recursos virtuais estavam disponíveis para o estudo extraclasse, na página da instituição, com acesso livre. Ao final do semestre letivo, foram avaliados pelos alunos, considerando os critérios anteriormente expostos.

Contadores WidgetContador permitem acompanhar o número de acessos e a sua distribuição geográfica.

\section{RESULTADOS E DISCUSSÃO}

Na teoria das inteligências múltiplas, Gardner propõe que os seres humanos possuem uma série de capacidades cognitivas relativamente autônomas. Essas capacidades diversas de processamento da informação, as quais ele designa como inteligências, foram desenvolvidas para resolver problemas ou criar produtos. Cada inteligência representa uma forma distinta de representação mental. A inteligência linguística possibilita desenvoltura no uso da linguagem falada e escrita e na aprendizagem de línguas estrangeiras. A inteligência lógico-matemática permite a análise de problemas com lógica e a resolução de operações matemáticas. A inteligência musical envolve facilidade na percepção e na produção da música. A inteligência espacial permite criar representações ou imagens mentais espaciais e operar sobre elas. A inteligência físicocinestésica é a habilidade de resolver problemas ou criar produtos usando o corpo ou partes dele. A inteligência naturalista envolve a habilidade de fazer discriminações consequenciais, baseia-se em capacidades que detectam padrões. A inteligência interpessoal é a capacidade de entender as intenções, as motivações e os desejos do próximo e, consequentemente, de trabalhar de modo eficiente com terceiros. A

inteligência intrapessoal é a capacidade da pessoa se conhecer, de ter um modelo 
individual de trabalho eficiente e de usar essas informações para tomar decisões sensatas na vida. A inteligência espiritual/existencial envolve capacidades de formular e examinar questões sobre o sentido da vida e da morte, sobre a existência e a fé (Gardner, 2001; Gardner, 2005; Gardner, 2007).

As inteligências linguística e lógico-matemática são importantes para a aprendizagem no ensino com aulas expositivas, leitura, escrita e cálculo (Gardner, 2005). No entanto, nas Ciências Morfológicas, às quais pertencem as disciplinas de Biologia Celular e Histologia, o conteúdo é bastante visual, e as habilidades de reconhecimento, classificação e categorização são fundamentais para a sua compreensão. Por isso, a construção do recurso virtual foi baseada na inteligência naturalista. Pretendia-se possibilitar o exercício do estudante em reconhecer, comparar (e distinguir) e classificar as células (os tecidos ou os órgãos) conforme suas características estruturais e ainda relacionar seu aspecto morfológico com a sua atividade funcional.

A navegação do atlas digital foi inicialmente construída usando o programa Macromedia Flash. A relevância da informação visual na área morfológica fez com que as fotomicrografias e eletromicrografias fossem priorizadas no seu design, e seu acesso fosse facilitado através da organização em categorias típicas da área (Figura 1). Estudos mostram a importância da linguagem visual na aprendizagem (Mayer \& Gallini, 1990; McClean et al., 2005).

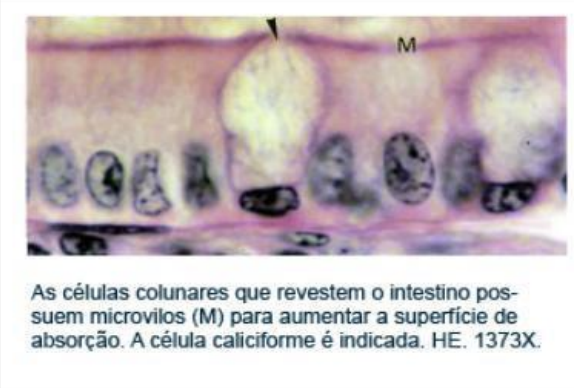

Figura 1 - Tela do tópico Célula na primeira versão do atlas digital.

Uma seção de exercícios foi agregada ao atlas, visando aumentar a interatividade do recurso virtual e motivar a aprendizagem. Com o auxílio do software Hot Potatoes, foram criados exercícios de escolha múltipla (quiz), associação, preenchimento de lacunas e palavras-cruzadas (Figuras 2 e 3). Os exercícios foram elaborados de modo a trazer conceitos e informações sobre as estruturas apresentadas, os processos e as funções das células e dos tecidos. $\mathrm{O}$ aluno constrói esse conhecimento à medida que interage com o exercício. Ainda, devido à sua programação, o aluno conhece a sua performance ao final da tarefa e, ciente de eventuais erros conceituais com retroalimentação imediata, pode revisar a matéria, o que envolve memorização e repetição, colaborando para a fixação do conteúdo. 
5
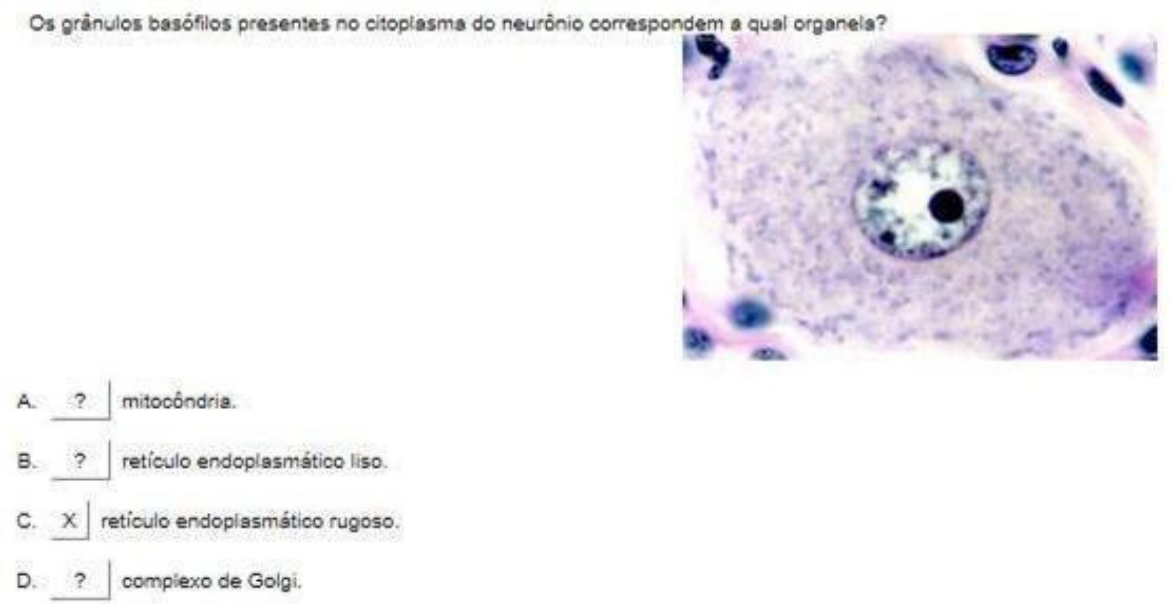

Figura 2 - Exercício de escolha múltipla com diagnóstico de imagem.

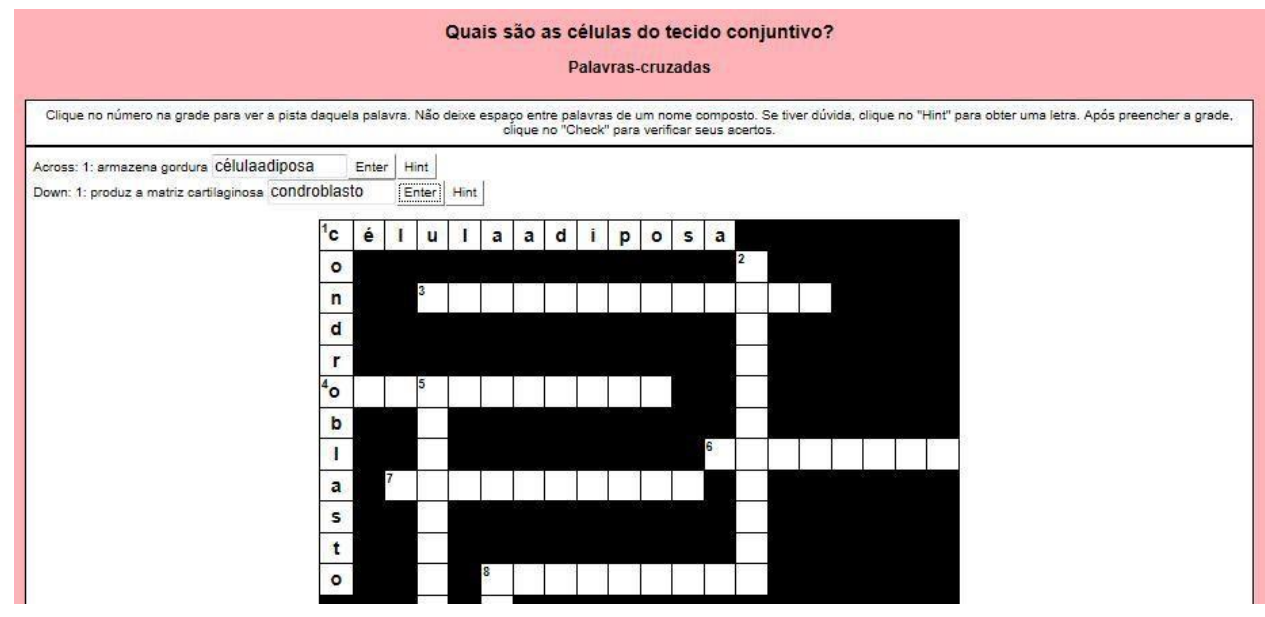

Figura 3 - Exercício de palavras-cruzadas.

O Atlas digital de Biologia celular e tecidual foi disponibilizado na página da instituição (http://www.ufrgs.br/atlasbiocel). Os resultados da avaliação discente são apresentados na Tabela 1. De um total de 34 alunos, 25 acessaram o atlas, realizaram os exercícios e responderam ao questionário de avaliação. A não participação dos demais remete às considerações de Gardner sobre a resistência ao aprendizado: "As pessoas relutam em alterar as práticas com quais foram criadas e com as quais já estão confortáveis demais" (Gardner, 2007, p. 136). Esses alunos, ao estudar para as provas, consultaram os livros da área ou se limitaram a revisar suas anotações de aula, como os desenhos realizados nas atividades práticas. 


\section{6}

Tabela 1 - Resultados da avaliação discente da primeira versão do atlas digital.*

\begin{tabular}{|c|c|c|c|c|}
\hline Critério avaliado & Sim & Parcialmente & Não & $\begin{array}{l}\text { Não } \\
\text { responderam }\end{array}$ \\
\hline Relevância para os objetivos da disciplina & $88 \%$ & $12 \%$ & & \\
\hline Motivação para o estudo do conteúdo & $80 \%$ & $20 \%$ & & \\
\hline $\begin{array}{l}\text { Contribuição das imagens para a identificação de } \\
\text { detalhes na morfologia das células }\end{array}$ & $80 \%$ & $20 \%$ & & \\
\hline $\begin{array}{l}\text { Contribuição para a compreensão da relação entre } \\
\text { forma e função }\end{array}$ & $84 \%$ & $16 \%$ & & \\
\hline \multicolumn{5}{|l|}{ Facilidade de orientação na navegação: } \\
\hline $\begin{array}{l}\text { Localização de informações para estudo e pesquisa } \\
\text { do conteúdo }\end{array}$ & $80 \%$ & $16 \%$ & $4 \%$ & \\
\hline $\begin{array}{l}\text { Facilidade da navegação pelo conjunto de telas } \\
\text { através do menu }\end{array}$ & $88 \%$ & $12 \%$ & & \\
\hline Acesso do conteúdo & $12 \%$ & $52 \%$ & $36 \%$ & \\
\hline \multicolumn{5}{|l|}{ Demora no tempo para baixar as telas: $32 \%$} \\
\hline Qualidade de nitidez das imagens & $80 \%$ & $20 \%$ & & \\
\hline \multicolumn{5}{|l|}{ Recursos para valorizar as imagens: } \\
\hline $\begin{array}{l}\text { Identificação das organelas e das estruturas através } \\
\text { de setas }\end{array}$ & $64 \%$ & $32 \%$ & $4 \%$ & \\
\hline Compreensão das legendas & $84 \%$ & $16 \%$ & & \\
\hline \multicolumn{5}{|l|}{$\begin{array}{l}\text { Incompreensão do texto: } 8 \% \text {; } \\
\text { tamanho da letra: } 4 \% \text {; outros fatores: } 4 \% \text {. }\end{array}$} \\
\hline $\begin{array}{l}\text { Contribuição dos exercícios para a compreensão do } \\
\text { conteúdo }\end{array}$ & $72 \%$ & $20 \%$ & & $8 \%$ \\
\hline $\begin{array}{l}\text { O atlas virtual é um recurso mais eficiente do que } \\
\text { um livro }\end{array}$ & $12 \%$ & $72 \%$ & $16 \%$ & \\
\hline \multicolumn{5}{|l|}{ Sobre a aplicação do conteúdo do atlas: } \\
\hline $\begin{array}{l}\text { Domínio do conjunto de informações para fazer uma } \\
\text { avaliação tranquila }\end{array}$ & $20 \%$ & $76 \%$ & & $4 \%$ \\
\hline Aplicação do conteúdo do atlas a outras disciplinas & $76 \%$ & $24 \%$ & & \\
\hline $\begin{array}{l}\text { Utilização das habilidades de estudo em ambiente } \\
\text { virtual exercitadas com o atlas em outras áreas do } \\
\text { curso ou da vida profissional }\end{array}$ & $72 \%$ & $28 \%$ & & \\
\hline
\end{tabular}

A maioria dos alunos considerou a navegação acessível, as fotografias de ótima qualidade e que as imagens e os exercícios favoreceram a compreensão do conteúdo, em especial, a relação entre morfologia e atividade funcional da célula, objetivo cognitivo definido na estratégia pedagógica. Sugestão frequente foi de que o atlas agregasse textos sobre as células e os tecidos mencionados. A avaliação ainda mostrou a necessidade de diminuir o tempo para baixar as imagens e de aumentar a sinalização das estruturas. 
Nova navegação do atlas digital foi elaborada com o Adobe Dreamwear, e arquivos criados no Word e salvos em $P D F$ foram publicados. As imagens foram acompanhadas de legendas e texto explicativo (Figura 4). A sinalização das estruturas foi ampliada.

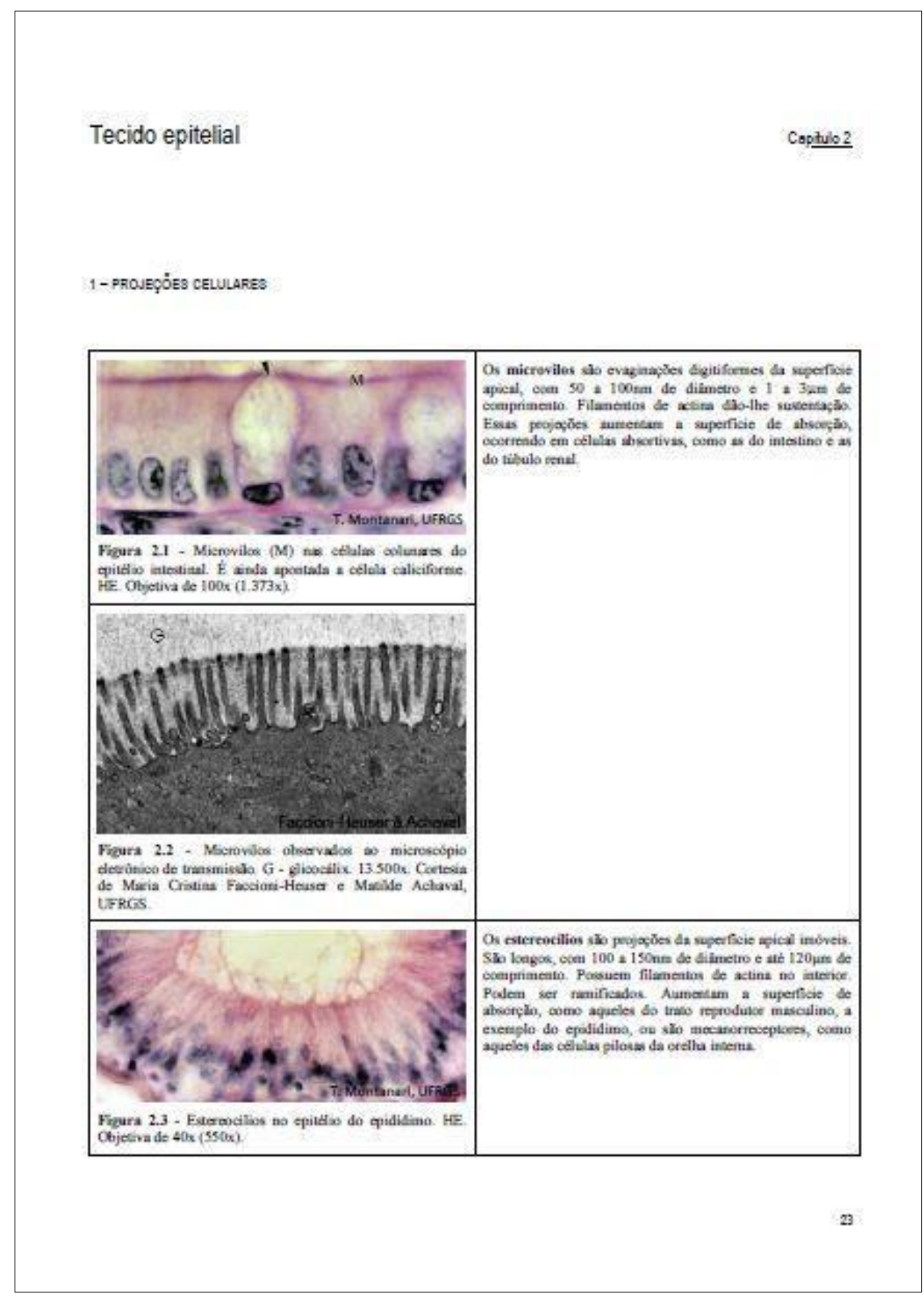

Figura 4 - Página do capítulo de Tecido Epitelial da versão final do atlas digital.

Um segundo recurso educacional foi desenvolvido com o Adobe Dreamwear, exibindo o conteúdo de Histologia em telas do PowerPoint (Figuras 5 e 6). Nele foram incluídos os exercícios elaborados com o programa Hot Potatoes. O auladehisto foi disponibilizado na página da instituição (http://www.ufrgs.br/auladehisto). 
8

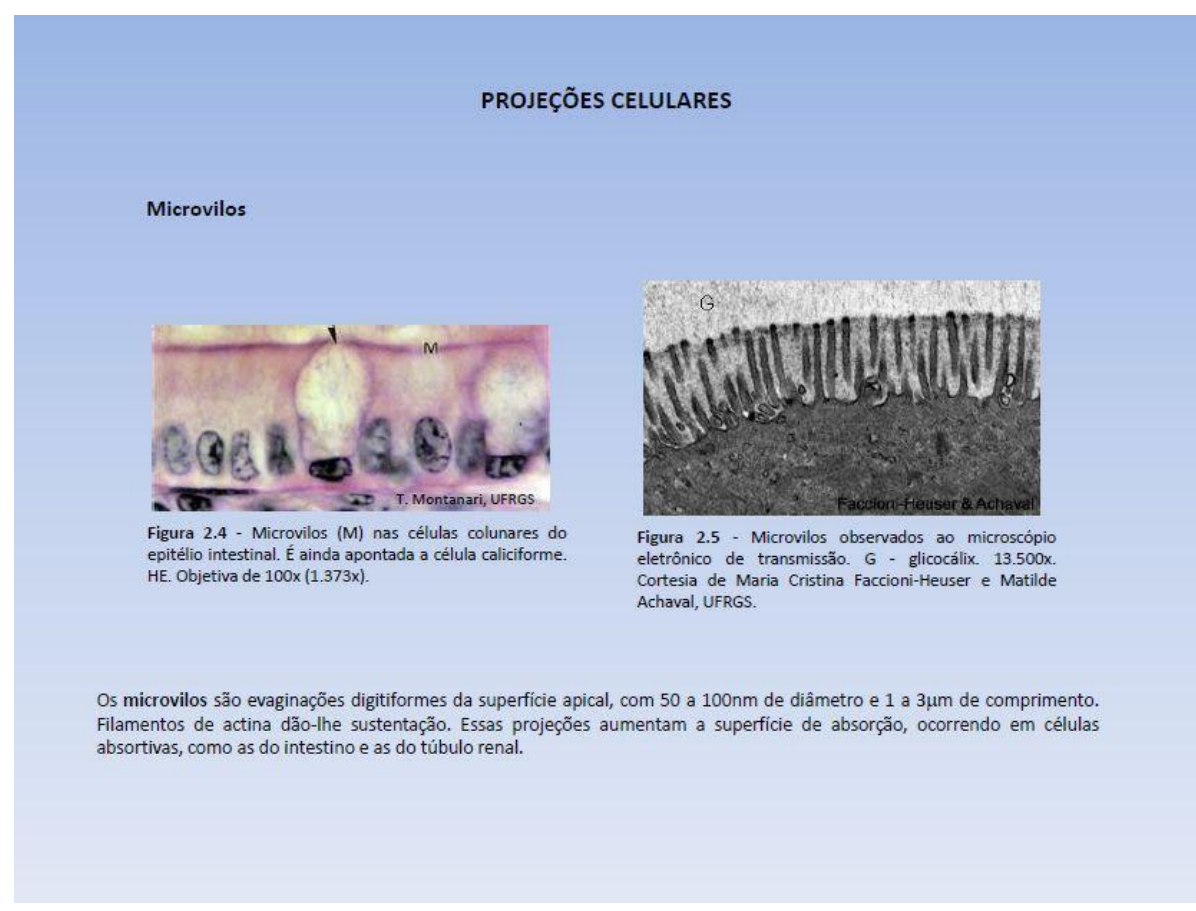

Figura 5 - Tela do capítulo de Tecido Epitelial, exibindo fotografias ao microscópio de luz e ao microscópio eletrônico.

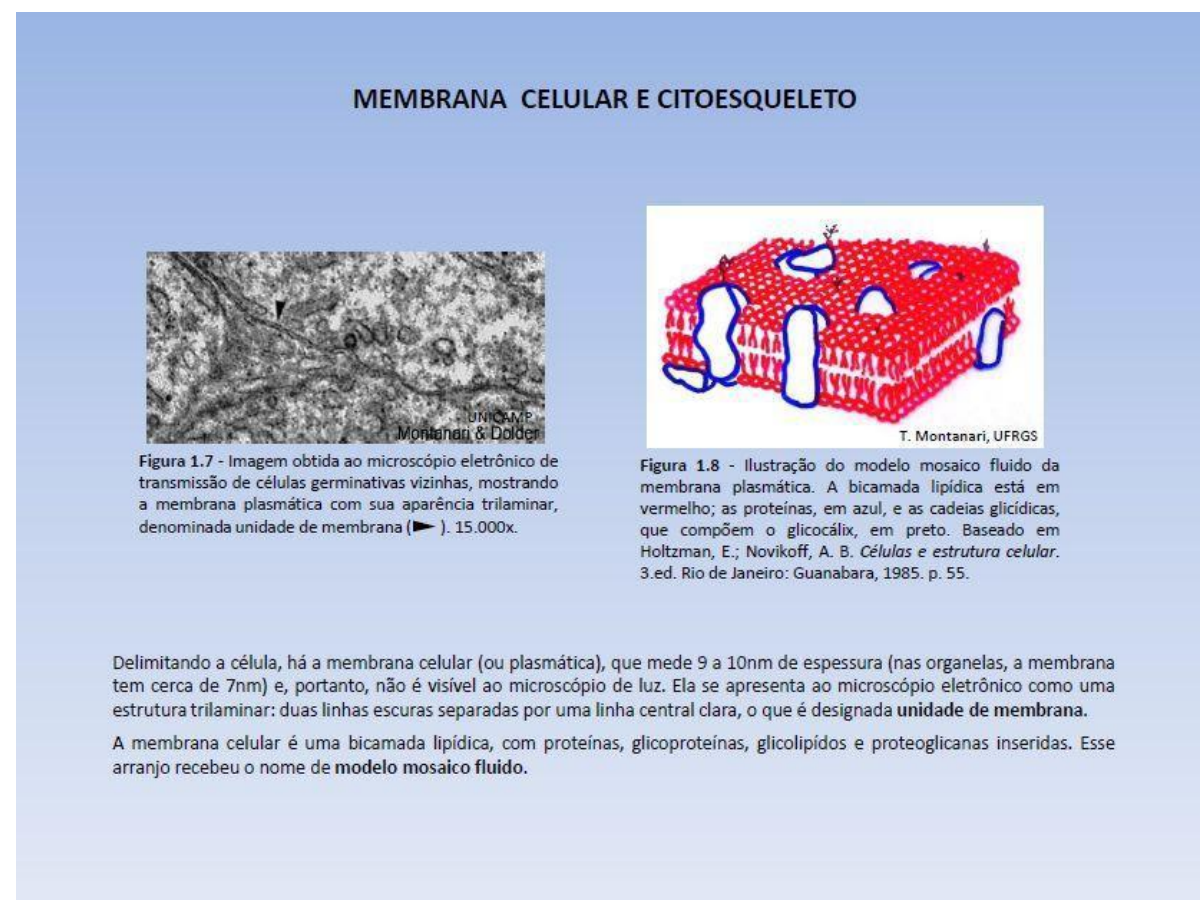

Figura 6 - Tela do capítulo de Célula, mostrando a inclusão de desenho de retroprojeção digitalizado.

Os recursos virtuais foram utilizados no primeiro semestre letivo de 2016 na disciplina Histologia do curso de Ciências Biológicas e pelos alunos avaliados (Tabelas 2 e 3). A maioria considerou que eles contribuíram para alcançar os objetivos da disciplina, possibilitando a identificação de detalhes na morfologia das células e a compreensão da relação entre a forma e a função das células. A navegação no Adobe 
Dreamweaver e a publicação de arquivos em $P D F$ deram rapidez para baixar as telas. Por outro lado, a atual versão do atlas diminuiu a motivação para o estudo, quando comparada com a anterior criada com o Macromedia Flash. O acréscimo de texto explicativo, embora tenha atendido sugestão dos alunos, e a apresentação do conteúdo em páginas sequencias tornaram o recurso um livro digital, suprimindo o seu aspecto lúdico. O ambiente virtual auladehisto, que apresenta o conteúdo em telas de Powerpoint e os exercícios elaborados no Hot Potatoes, foi considerado mais estimulante para o estudo e foi mais acessado do que o atlas digital.

Tabela 2 - Resultados da avaliação discente da segunda versão do atlas digital.*

\begin{tabular}{|c|c|c|c|c|}
\hline Critério avaliado & Sim & Parcialmente & Não & $\begin{array}{c}\text { Não } \\
\text { responderam }\end{array}$ \\
\hline $\begin{array}{l}\text { O Atlas contribuiu para alcançar os objetivos da } \\
\text { disciplina? }\end{array}$ & $73,9 \%$ & $26,1 \%$ & & \\
\hline Ele motivou o estudo do conteúdo? & $21,7 \%$ & $65,2 \%$ & $13,1 \%$ & \\
\hline $\begin{array}{l}\text { As imagens contribuíram para a identificação de } \\
\text { detalhes na morfologia das células? }\end{array}$ & $82,6 \%$ & $17,4 \%$ & & \\
\hline $\begin{array}{l}\text { O Atlas contribuiu para a compreensão da relação } \\
\text { entre forma e função? }\end{array}$ & $73,9 \%$ & $26,1 \%$ & & \\
\hline \multicolumn{5}{|l|}{ Facilidade de orientação na navegação: } \\
\hline $\begin{array}{l}\text { As informações foram facilmente encontradas para } \\
\text { estudo e pesquisa do conteúdo? }\end{array}$ & $73,9 \%$ & $21,7 \%$ & $4,4 \%$ & \\
\hline $\begin{array}{l}\text { O menu permitiu a navegação pelo conjunto de telas } \\
\text { com facilidade? }\end{array}$ & $82,6 \%$ & $17,4 \%$ & & \\
\hline Teve alguma dificuldade para acessar o conteúdo? & $8,7 \%$ & $4,3 \%$ & $87 \%$ & \\
\hline Por ex., demora para baixar as telas? & & $8,7 \%$ & $91,3 \%$ & \\
\hline \multicolumn{5}{|l|}{ Recursos para valorizar as imagens: } \\
\hline As imagens são nítidas? & $69,6 \%$ & $30,4 \%$ & & \\
\hline $\begin{array}{l}\text { Os tecidos, as células e os seus constituintes foram } \\
\text { adequadamente identificados através de setas? }\end{array}$ & $65,2 \%$ & $34,8 \%$ & & \\
\hline As legendas e o texto foram bem compreendidos? & $56,5 \%$ & $34,8 \%$ & $8,7 \%$ & \\
\hline O tamanho da letra foi adequado? & $91,3 \%$ & $4,4 \%$ & & $4,3 \%$ \\
\hline \multicolumn{5}{|l|}{ Sobre a aplicação do conteúdo: } \\
\hline $\begin{array}{l}\text { Você acredita que domina o conteúdo para fazer } \\
\text { uma avaliação tranquila? }\end{array}$ & $17,4 \%$ & $65,2 \%$ & $17,4 \%$ & \\
\hline $\begin{array}{l}\text { Aplicou (ou acredita que aplicará) o conteúdo a } \\
\text { outras disciplinas? }\end{array}$ & $56,5 \%$ & $34,8 \%$ & $8,7 \%$ & \\
\hline $\begin{array}{l}\text { Utilizará as habilidades de estudo em ambiente } \\
\text { virtual em outras áreas do curso ou da vida } \\
\text { profissional? }\end{array}$ & $60,9 \%$ & $39,1 \%$ & & \\
\hline
\end{tabular}

* Disciplina Histologia do curso de Ciências Biológicas, $1^{\circ}$ semestre de 2016, 23 alunos. 
10

Tabela 3 - Resultados da avaliação discente do ambiente virtual auladehisto.*

\begin{tabular}{|c|c|c|c|c|}
\hline Critério avaliado & Sim & Parcialmente & Não & $\begin{array}{l}\text { Não } \\
\text { responderam }\end{array}$ \\
\hline $\begin{array}{l}\text { O auladehisto contribuiu para alcançar os objetivos } \\
\text { da disciplina? }\end{array}$ & $60,6 \%$ & $39,4 \%$ & & \\
\hline Ele motivou o estudo do conteúdo? & $57,6 \%$ & $39,4 \%$ & $3 \%$ & \\
\hline $\begin{array}{l}\text { As imagens contribuíram para a identificação de } \\
\text { detalhes na morfologia das células? }\end{array}$ & $78,8 \%$ & $18,2 \%$ & $3 \%$ & \\
\hline $\begin{array}{l}\text { O auladehisto contribuiu para a compreensão da } \\
\text { relação entre forma e função? }\end{array}$ & $60,6 \%$ & $36,4 \%$ & & $3 \%$ \\
\hline \multicolumn{5}{|l|}{ Facilidade de orientação na navegação: } \\
\hline $\begin{array}{l}\text { As informações foram facilmente encontradas para } \\
\text { estudo e pesquisa do conteúdo? }\end{array}$ & $78,8 \%$ & $18,2 \%$ & & $3 \%$ \\
\hline $\begin{array}{l}\text { O menu permitiu a navegação pelo conjunto de telas } \\
\text { com facilidade? }\end{array}$ & $78,8 \%$ & $18,2 \%$ & & $3 \%$ \\
\hline Teve alguma dificuldade para acessar o conteúdo? & $9,1 \%$ & $3 \%$ & $87,9 \%$ & \\
\hline Por ex., demora para baixar as telas? & $3 \%$ & $9,1 \%$ & $87,9 \%$ & \\
\hline \multicolumn{5}{|l|}{ Recursos para valorizar as imagens: } \\
\hline As imagens são nítidas? & $69,7 \%$ & $30,3 \%$ & & \\
\hline $\begin{array}{l}\text { Os tecidos, as células e os seus constituintes foram } \\
\text { adequadamente identificados através de setas? }\end{array}$ & $54,5 \%$ & $45,5 \%$ & & \\
\hline As legendas e o texto foram bem compreendidos? & $57,6 \%$ & $39,4 \%$ & $3 \%$ & \\
\hline O tamanho da letra foi adequado? & $87,9 \%$ & $9,1 \%$ & & $3 \%$ \\
\hline \multicolumn{5}{|l|}{ Sobre a aplicação do conteúdo: } \\
\hline $\begin{array}{l}\text { Você acredita que domina o conteúdo para fazer } \\
\text { uma avaliação tranquila? }\end{array}$ & $9,1 \%$ & $63,6 \%$ & $27,3 \%$ & \\
\hline $\begin{array}{l}\text { Aplicou (ou acredita que aplicará) o conteúdo a } \\
\text { outras disciplinas? }\end{array}$ & $45,4 \%$ & $48,5 \%$ & $6,1 \%$ & \\
\hline $\begin{array}{l}\text { Utilizará as habilidades de estudo em ambiente } \\
\text { virtual em outras áreas do curso ou da vida } \\
\text { profissional? }\end{array}$ & $63,6 \%$ & $30,3 \%$ & $6,1 \%$ & \\
\hline
\end{tabular}

Espera-se, com o desenvolvimento do Atlas digital de Biologia celular $e$ tecidual e do ambiente virtual auladehisto, apresentando informação qualificada e atualizada, ricamente ilustrada e com recursos de interatividade, ter contribuído para o processo de aprendizagem no ensino presencial e remoto da disciplina de Histologia e, por conseguinte, para a qualificação do ensino das Ciências Morfológicas.

\section{CONCLUSÕES}

Foram produzidos dois recursos virtuais sobre Histologia, cuja prioridade, no design, foi 
11

a linguagem visual. $\mathrm{O}$ acesso livre pela internet possibilita o estudo extraclasse, tornando o aluno sujeito ativo no processo de aprendizagem. Os exercícios contribuem para a construção do conhecimento de forma interativa. A avaliação discente da sua aplicabilidade indicou que o objetivo cognitivo de promover a compreensão do conteúdo, em especial, a relação entre morfologia e atividade funcional da célula, foi alcançado.

\section{AGRADECIMENTOS}

A Eliane de Oliveira Borges (Departamento de Fisiologia, ICBS, UFRGS) pela orientação com o programa Hot Potatoes, pelas ilustrações dos sistemas digestório, respiratório e urinário realizadas no Adobe Illustrator e pelo desenvolvimento da navegação da versão final do atlas digital e do auladehisto. A Diorlon Nunes Machado (monitor do programa de educação a distância para disciplina presencial, PROGRAD/SEAD, UFRGS - 2016) e a Alexandre Morales (técnico de Tecnologia da Informação do ICBS, UFRGS) pela navegação do auladehisto. A Raymundo Carlos Machado Ferreira pela navegação dos exercícios; a Gabriela Perry pelo desenvolvimento do design e da navegação da primeira versão do atlas; a Sofia Louise Santin Barilli pela digitalização da maioria das fotomicrografias, e a Leonardo Lisbôa da Motta pela digitalização de parte das eletromicrografias e pela publicação das imagens e das legendas na primeira versão do atlas digital.

Às Prof ${ }^{\text {as }}$ Maria Cristina Faccioni Heuser, Matilde Achaval, Tais Malysz, Patrícia Nascimento e Fabiana Rigon por várias das eletromicrografias que ilustram o atlas, e à Prof ${ }^{\mathrm{a}}$ Simone Marcuzzo e aos seus orientados Francele Valente Piazza e André Luís Ferreira de Meireles pela fotomicrografia do neurônio ao microscópio confocal exibida na tela de navegação e na capa do atlas digital.

À Secretaria de Educação a Distância (SEAD) da UFRGS pelo apoio através de bolsa aos acadêmicos Leonardo Lisbôa da Motta em 2007 e Diorlon Nunes Machado em 2016.

Agradecimento póstumo à Dra Maria Isabel Timm (CESUP, UFRGS) pela coordenação da primeira versão do projeto.

\section{REFERÊNCIAS BIBLIOGRÁFICAS}

ALBERTS, B.; JOHNSON, A.; LEWIS, J.; RAFF, M.; ROBERTS, K.; WALTER, P. Biologia Molecular da Célula. 5.ed. Porto Alegre: Artmed, 2010. 1396 p.

CARVAlHO, H. F.; RECCO-PIMENTEL, S. A Célula. 3.ed. Barueri: Manole, 2013. p.1-2.

GARDNER, H. Inteligência: um conceito reformulado. Rio de Janeiro: Objetiva, 2001. $347 \mathrm{p}$.

GARDNER, H. Mentes que mudam: a arte e a ciência de mudar as nossas idéias e a dos outros. Porto Alegre: Artmed/Bookman, 2005. 229 p.

GARDNER, H. Cinco mentes para o futuro. Porto Alegre: Artmed, 2007. 160 p.

GENESER, F. Histologia: com bases moleculares. 3.ed. Buenos Aires: Médica Panamericana/ Rio de Janeiro: Guanabara Koogan, 2003. 616 p.

HEIDGER Jr., P. M.; DEE, F.; CONSOER, D.; LEAVEN, T.; DUCAN, J.; KREITER, 
C. Integrated approach to teaching and testing in Histology with real and virtual imaging. The Anatomical Record, v.269, p.107-112, 2002.

LOWE, J. S.; ANDERSON, P. G. Stevens \& Lowe's Human Histology. 4.ed. Philadelphia: Elsevier, Mosby, 2015. 429 p.

MAYER, R. E.; GALLINI, J. K. When is an illustration worth ten thousand words? Journal of Educational Psychology, v.82, n.4, p.715-726, 1990.

MCCLEAN, P.; JOHNSON, C.; ROGERS, R.; DANIELS, L.; REBER, J.; SLATOR, B. M.; TERPSTRA, J.; WHITE, A. Molecular and cellular Biology animations: development and impact on student learning. Cell Biology Education, v.4, p.169-179, 2005.

ROSS, M. H.; PAWLINA, W. Histologia: texto e atlas, correlações com Biologia celular e molecular. 7.ed. Rio de Janeiro: Guanabara Koogan, 2016. p.1, 23, 98.

SANTA-ROSA, J. G.; STRUCHINER, M. Tecnologia educacional no contexto do ensino de Histologia: pesquisa e desenvolvimento de um ambiente virtual de ensino e aprendizagem. Revista Brasileira de Educação Médica, v.35, n.2, p 289-298, 2011.

STITH, B. J. Use of animation in teaching Cell biology. Cell Biology Education, v.3, p.181-188, 2004. 